\title{
On the Relationship between Perfectionism and College Students' Academic Procrastination: The Moderating Role of Causality Orientations
}

\author{
Dongchun $\mathrm{ZHU}^{1}$ Guirong LIU $^{2 *}$ \\ 1. Shandong Dong Heng Colloidal Material Co. Ltd., Jinan Shandong, 250000 \\ 2. Teacher Education Department, Qilu Normal University, Jinan Shandong 250200
}

\begin{abstract}
Based on Self-determination Theory (SDT), this study attempted to explore the relationship between perfectionism and college students' academic procrastination as well as moderating role of causality orientations. A total of 660 undergraduates in three majors from two universities in Jinan, Shandong province participated in the questionnaire survey. The results indicated that: (1) positive perfectionism was significantly negatively correlated with academic procrastination while negative perfectionism was significantly positively correlated with procrastination; (2) controlled orientation and impersonal orientation were all significantly positively correlated with academic procrastination; (3) controlled orientation moderated the relationship between negative perfectionism and college students' academic procrastination: negative perfectionism can't predict academic procrastination when controlled orientation was low; negative perfectionism can't predict academic procrastination when controlled orientation was high; and (4) impersonal orientation moderated the relationship between negative perfectionism and college students' academic procrastination: negative perfectionism can't predict academic procrastination when impersonal orientation was low; negative perfectionism significantly positively predicted academic procrastination when impersonal orientation was high.
\end{abstract}

Keywords-Perfectionism; Causality Orientation; Academic Procrastination

\section{QUESTION RAISING}

Academic procrastination is the procrastination that takes place in school and is correlated with the completion of learning tasks [1]. Academic procrastination can bring students a series of negative consequences, such as increasing their stress and discouraging their academic performance. Therefore, many researchers have paid attention to the factors causing academic procrastination and domestic and foreign scholars have found the influence of perfectionism on academic procrastination among many personality traits [2-4].

Perfectionism is a personality trait, which makes students complete the task to a high standard, and accompanied with a critical self-evaluation tendency [5]. Frost et al. (1990) divided perfectionism into 6 dimensions of worrying about mistakes, behavioral doubts, organization, personal standards, parental expectations and parental criticism [5]. In the process of revising Chinese version, ZI and ZHOU (2006) further regarded the organization as positive perfectionism and worrying about mistakes, behavioral doubts, personal standards, parental expectations and parental criticism as negative perfectionism [6]. The study of Chen et al. (2013) found that positive perfectionism significantly negatively predicted college students' academic procrastination, negative perfectionism significantly positively predicted academic procrastination, and found that self-esteem and other variables played a partial intermediary role between perfectionism and academic procrastination [3]. The result suggested that there were more paths for perfectionism to affect the academic procrastination than self-esteem, and that there may be other factors that influence the relationship between the two.

Self-determination theory (SDT) is a general theory about human motivation, which emphasized whether the behavior was driven internally or externally [7-8]. There are many sub-theories under the SDT framework, among which the causality orientations theory is an important one. The causality orientation refers to the individual's tendency to specific environmental stimuli, the activation and regulation of behaviors, and the individual's self-determination degree in various situations and fields [9]. Many theoretical and empirical studies under the SDT framework have found that individuals have three causality orientations: Autonomous orientation, controlled orientation and impersonal orientation [7]. Specifically, autonomous orientation means the individuals have the tendency to hold informative feedback and have internal control points; Controlled orientation means that the individuals hold that their behaviors are driven by internal (" should ") or external pressure (time limit, rewards, rules or needs of others). The individuals with controlled orientation are more sensitive to the requirements of others than their own needs and preferences; Impersonal orientation means that the individuals trend to believe that results are uncontrollable and that achievements are more attributed to the luck or fate.

Academic procrastination is closely correlated with individual's motivation. The study found that internal motivation was significantly negatively correlated with academic procrastination, while external motivation was significantly positively correlated with academic procrastination. Compared with situational motivation, the causality orientation has the stability of personality traits. The relationship between causality orientation and academic procrastination has not been studied and discussed. As 
previously mentioned, the relationship between perfectionism and academic procrastination may be influenced by a third variable. Causality orientation may be a third variable influencing the relationship between the two. Based on the above considerations, this study will examine the relationship between perfectionism and college students' academic procrastination and the possible moderating role of causality orientation on the relationship between them.

\section{METHOD}

\section{A. Participants}

A total of 660 undergraduates in three majors from two universities in Shandong were selected as participants by cluster random sampling. There were 285 boys and 375 girls; There were 260 freshmen, 230 sophomore students and 170 junior students. All participants were aged 20.35 \pm 0.50 .

\section{B. Research Tools}

\section{1) Perfectionism}

The Chinese version of Frost Multidimensional Perfectionism Scale (FMPS) was adopted to measure the perfectionism [6]. The questionnaire consisted of 27 items, with a five-point scale and included five dimensions of organization, personal standards, behavioral doubts, parental expectations and worrying about mistakes. The "organization" was as positive perfectionism and other four dimensions were as negative perfectionism. The questionnaire had a good reliability index in this study, with a total reliability of 0.86 . The reliability of the five dimensions was $0.80,0.76,0.66,0.74$ and 0.87 , respectively.

\section{2) Causality Orientation}

The General Causality Orientations Scale (GCOS) was adopted to measure the degree of college students' autonomous orientation, controlled orientation and impersonal orientation. The Scale includes 12 situations, and there were 3 orientation problems aiming at measuring 3 orientations for each situation, with a total of 36 items. The students were required to answer on the seven-point scale. The scores on three orientations were calculated separately. The higher the score was, the stronger the orientation was. The questionnaire was compiled by Deci and Ryan (1985) [7], and revised by LIU, ZHANG and WANG (2012) [10]. The questionnaire had good reliability and validity and can be used to measure the characteristics of the general causality orientation of college students. The reliability of the autonomous orientation, controlled orientation and impersonal orientation was $0.82,0.62$ and 0.75 respectively in this study.

\section{3) Academic Procrastination}

12 questions in Part I of student version of Procrastination Assessment Scale Students (PASS) were adopted to measure the procrastination frequency and severity of students on six learning tasks, with a five-point scale. The total reliability was 0.85 in this study.

\section{Procedures}

After obtaining the consent of the school and students, this study took the class as the unit to implement the group testing. The field testing was conducted by means of overall testing. Each class was in the charge of two experimenters, the students completed the questionnaire independently, lasting 20 minutes and then the questionnaire was collected on the spot. The statistical analysis was conducted on the data by using Lisrel 8.70 and SPSS22.0. With reference to relevant studies [11], the significance of all regression coefficients in this study was tested by Bootstrap method.

\section{RESULTS}

\section{A. Descriptive Statistics and Correlation Analysis of Perfectionism, Causality Orientation and Academic Procrastination}

Table 1 presents the correlation matrix of all variables. It can be seen from the table that (1) in terms of the correlation between perfectionism and academic procrastination, positive perfectionism was significantly negatively correlated with academic procrastination, while negative perfectionism was significantly positively correlated with academic procrastination. (2) In terms of the correlation between causality orientation and academic procrastination, controlled orientation and impersonal orientation were all significantly positively correlated with academic procrastination. (3) In terms of the correlation between perfectionism and causality orientation, positive perfectionism was significantly positively correlated with the autonomous orientation, while it was significantly negatively correlated with the impersonal orientation; Negative perfectionism was significantly positively correlated with controlled orientation and impersonal orientation.

TABLE I CORRELATION MATRIX OF PERFECTIONISM, CAUSALITY ORIENTATION AND ACADEMIC PROCRASTINATION

\begin{tabular}{|c|c|c|c|c|c|c|}
\hline Variables & 1 & 2 & 3 & 4 & 5 & 6 \\
\hline $\begin{array}{l}\text { 1.Positive } \\
\text { perfectionism }\end{array}$ & 1 & & & & & \\
\hline $\begin{array}{l}\text { 2.Negative } \\
\text { perfectionism }\end{array}$ & $0.17 * * *$ & 1 & & & & \\
\hline $\begin{array}{l}\text { 3.Autonomous } \\
\text { orientation }\end{array}$ & $0.27 * * *$ & 0.01 & 1 & & & \\
\hline $\begin{array}{l}\text { 4.Controlled } \\
\text { orientation }\end{array}$ & 0.06 & $0.26 * * *$ & $0.36 * * *$ & 1 & & \\
\hline $\begin{array}{l}\text { 5.Impersonal } \\
\text { orientation }\end{array}$ & $-0.11 * *$ & $0.33 * * *$ & $-0.11 * *$ & $0.41 * * *$ & 1 & \\
\hline
\end{tabular}


Table I, cont

\begin{tabular}{lllllll} 
6.Academic & $-0.11^{* *}$ & $0.18^{* * *}$ & 0.00 & $0.11^{* *}$ & $0.22^{* * *}$ & 1 \\
procrastination & & & & & & \\
M & 3.81 & 2.82 & 5.34 & 4.09 & 3.47 & 2.89 \\
SD & 0.68 & 0.62 & 0.90 & 0.76 & 0.89 & 0.75 \\
\hline
\end{tabular}

Note: ${ }^{*}$ represents $p<0.05{ }^{* *}$ represents $p<0.01$ and ${ }^{* * *}$ represents $p<0.001$, the same below. Correlation coefficients were obtained by Bootstrap method.

B. Predictive Effect of Perfectionism and Causality

Orientation on Academic Procrastination

The hierarchical regression was adopted to examine the predictive effect of perfectionism and causality orientation on college students' academic procrastination and the possible moderating role of causality orientation. Firstly, the gender, major and grade of students were included in the model as the first layer. Secondly, the positive perfectionism, negative perfectionism, autonomous orientation, controlled orientation and impersonal orientation were included in the second layer to examine the predictive effect of perfectionism and causality orientation on college students' academic procrastination. Finally, all dimensions of perfectionism and causality orientation are centralized, and then the product terms of centralization variables were constructed to be included in the model to examine the moderating role of causality orientation between perfectionism and academic procrastination. (See Table 2).

The results showed that gender, grade and major could not significantly predict college students' academic procrastination (Model 1); Positive perfectionism significantly negatively predicted academic procrastination $(\beta$ was $-0.13, p<0.001)$, negative perfectionism and impersonal orientation significantly positively predicted academic procrastination ( $\beta$ was 0.15 and $0.17, p<0.001)$, which could explain the variation of $8 \%$ academic orientation (Model 2); Controlled orientation moderated the relationship between negative perfectionism and academic procrastination $(\beta$ was $-0.14, \quad p<0.05)$, and impersonal orientation moderated the relationship between positive perfectionism and academic procrastination $(\beta$ was 0.15 and $p<0.01)$, which could explain the variation of $2 \%$ academic procrastination (Model 3).
TABLE II

PREDICTIVE EFFECT OF PERFECTIONISM AND CAUSALITY ORIENTATION ON ACADEMIC PROCRASTINATION

\section{$B \quad R^{2} \Delta R^{2}$}

\section{Step 1}

Gender $^{\text {a }}$

Major ${ }^{b}$

Grade $^{c}$

Step 2

Positive perfectionism

Negative perfectionism

Autonomous orientation .06

Controlled orientation

Impersonal orientation $.17^{* * *}$

$.08^{* * *}$

$.08^{* * *}$

Step 3

Positive perfectionism $\times$ Autonomous orientation $\times$

Positive perfectionism $\times$ Controlled orientation $\times$

Positive perfectionism $\times$ Impersonal orientation $\times$

Negative perfectionism $\times$ Autonomous orientation $\times$

Negative perfectionism $\times$ Controlled orientation $\times$

$-.14^{*}$

Negative perfectionism $\times$ Impersonal orientation $\times$ 
The simple slope analysis was carried out on the moderating role of controlled orientation [12] (Figure 1). Negative perfectionism can positively predict the academic procrastination when controlled orientation was low (simple slope $=0.26, t=2.62, p<0.01)$; Negative perfectionism can't predict the academic procrastination when controlled orientation was high ( simple slope $=0.09, t=0.82, p>0.05$ ).
The simple slope analysis was carried out on the regulation function of impersonal orientation. Negative perfectionism can't predict the academic procrastination when impersonal orientation was low (simple slope $=-0.05, t=-0.6, p>0.05$ ); Negative perfectionism can significantly positively predict the academic procrastination when impersonal orientation was high ( simple slope $=0.26, t=2.82, p<0.01$ ).

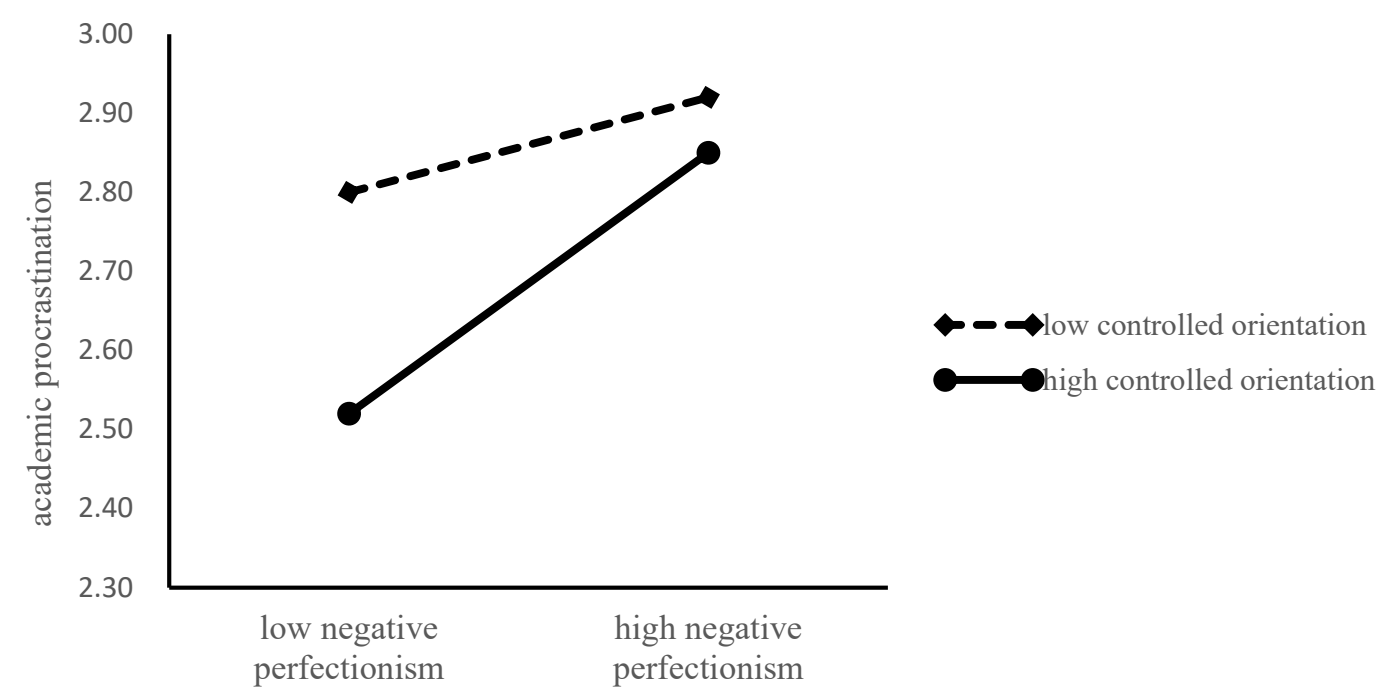

Fig. 1 Moderating role of controlled orientation on the relationship between negative perfectionism and academic procrastination

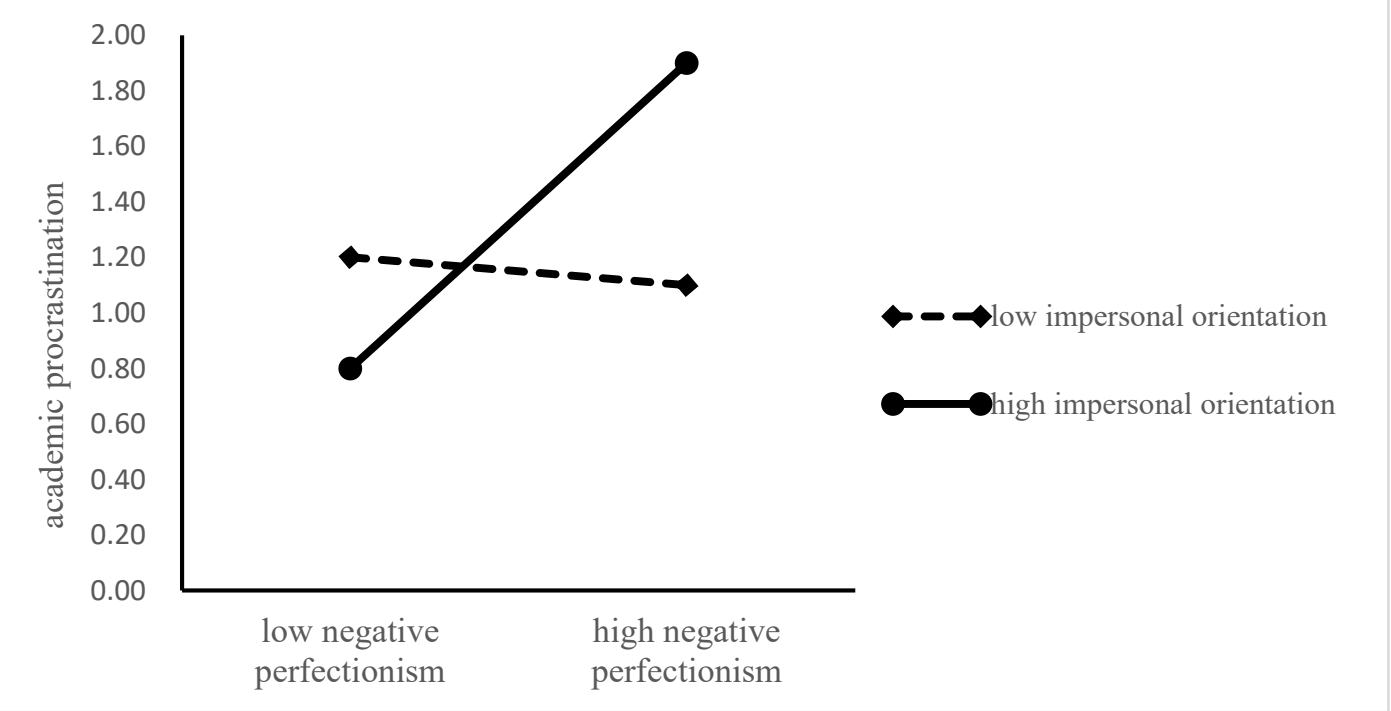

Fig. 2 Moderating role of impersonal orientation on the relationship between negative perfectionism and academic procrastination 


\section{DISCUSSION}

Both correlation analysis and regression analysis found that positive perfectionism significantly negatively predicted academic procrastination and negative perfectionism significantly positively predicted academic procrastination. This is consistent with relevant studies at home and abroad [3] [4] [13]. This shows that excessive worrying about mistakes, doubts about their own actions, higher personal standards and perceived high parental expectations all brought troubles to college students' academic completion and caused academic procrastination; Organization helped college students to complete academic tasks and reduce academic procrastination.

This study found that impersonal orientation significantly positively predicted academic procrastination, while autonomous orientation and controlled orientation had no significant predictive effect on academic procrastination. Previous studies have indicated that three causality orientations were associated with different behaviors and results. A study found that autonomous orientation significantly positively predicted academic performance of vocational college students, controlled orientation significantly positively predicted academic performance, and impersonal orientation can't predict academic performance [10]. According to the results of this study, academic procrastination as a process indicator and academic performance as a result indicator are of different structures and have different influencing factors and internal mechanisms. We can infer from two studies that autonomous orientation and controlled orientation can't directly predict the process (such as academic procrastination), but can directly affect the results (such as academic achievement); Impersonal orientation can directly predict the process, but not the results. Future studies can further verify the relationship between causality orientation and academic process, academic results.

The analysis of moderating role of causality orientation between perfectionism and academic procrastination indicated that controlled orientation moderated the relationship between negative perfectionism and academic delay. Negative perfectionism positively predicted academic procrastination when controlled orientation was low; Negative perfectionism can't predict college students' academic procrastination when controlled orientation was high. The results of the moderating indicated that high controlled orientation could buffer the prediction of negative perfectionism on academic procrastination. For individuals with high controlled orientation, stress, external requirements, and expectations were exactly the motivations of their actions, and these motivations mitigated the academic procrastination caused by negative perfectionism (doubt, worrying about mistakes, unrealistic standards, etc.). In addition, impersonal orientation also moderated the relationship between negative perfectionism and academic procrastination. Negative perfectionism positively predicted academic procrastination when impersonal orientation was high; Negative perfectionism can't predict academic procrastination when impersonal orientation was low. This suggested that impersonal orientation enhanced the prediction of negative perfectionism on academic procrastination. The individuals with high impersonal orientation tended to think that events were uncontrollable and were helpless in the face of difficulties. These performances intensified the predictive effect of negative perfectionism on academic procrastination.

The moderating role of causality orientation to perfectionism and academic procrastination was the greatest practical value or inspiration of this study. This inspired researchers and university administrators to take full account of their causality orientations, especially the positive role of controlled orientation and the negative role of impersonal orientation, when viewing the relationship between perfectionism and academic procrastination, especially the relationship between negative perfectionism and academic procrastination [14].

\section{CONCLUSION}

(1) Positive perfectionism was significantly negatively correlated with academic procrastination, while negative perfectionism was significantly negatively correlated with academic procrastination.

(2) Controlled orientation moderated the relationship between negative perfectionism and college students' academic procrastination.

(3) Impersonal orientation moderated the relationship between negative perfectionism and college students' academic procrastination.

\section{ACKNOWLEDGMENT}

This paper is supported by the research project of social science research plan of Shandong Province (17CJYJ08), "research on the impact of family system on migrant children adaptation" and by educational reform of Qilu Normal University "The application research of flipped classroom in university teaching — taking English in psychology as an example"(jg201703), and by bilingual teaching project of Qilu Normal University "English in psychology"(sykc201702), "curriculum and teaching theory in Primary English"(sykc201701), and by Shandong province university humanities project (J18RA167).

Corresponding author: Liu Guirong, Email: ganenxiaowai@163.com. 


\section{REFERENCES}

[1] Ferrari, J. R., Johnson, J. L., \& McCown, W. G. (1995). Procrastination and task avoidance: Theory, research, and treatment. NY, US: Plenum Press.

[2] Saddler, C. D., \& Buley, J. (1999). Predictors of academic procrastination in college students. Psychological Reports, 84(2), 686688.

[3] Chen, C., Yan, T., \& Lin, C. (2013). Perfectionism, self-esteem, and academic procrastination among Chinese university students. Psychological Development and Education, (4), 368-377.

[4] Miao, L., Yang, M., Zhao, K., Lei, X., Liu, S., \& Zhang, L. (2018). Effect of perfectionism on college students' academic procrastination: The moderated mediation model. Chinese Journal of Applied Psychology, 24(3), 252-260.

[5] Frost, R., Marten, P., Lahart, C., et al. (1990). The dimensions of perfectionism. Cognitive Therapy and Research, 14(5), 449-468.

[6] Zi, F., \& Zhou, X. (2006). The Chinese Frost Multidimensional Perfectionism Scale: An examination of its reliability and validity. Chinese Journal of Clinical Psychology, 14(6), 560-563.

[7] Deci, E. L., \& Ryan, R. M. (1985). The general causality orientations scale: Self-determination in personality. Journal of Research in Personality, 19, 109-134.

[8] Deci, E. L., \& Ryan, R. M. (2000). The "what" and "why" of goal pursuits: Human needs and the self-determination of behavior. Psychological Inquiry, 11, 319-338.

[9] Deci, E. L., \& Ryan, R. M. (2008). Self-determination theory: A macrotheory of human motivation, development, and health. Canadian Psychology, 49, 182-185.

[10] Liu, G., Zhang, J., \& Wang, H. (2012). Relationship between causality orientations and academic performance of vocational college students. Psychological Exploration, 32(1), 31-35.

[11] Erceg-Hurn, D. M., \& Mirosevich, V. M. (2008). Modern robust statistical methods: An easy way to maximize the accuracy and power of your research. American Psychologist, 63(7), 591-601.

[12] Preacher, K. J., Curran, P. J., \& Bauer, D. J. (2006). Computational tools for probing interactions in multiple linear regression, multilevel modeling, and latent curve analysis. Journal of Educational and Behavioral Statistics, 31, 437-448.

[13] Burns, L., R., Dittman, K., Nguyen, N., \& Mitchelson, J. K. (2000). Academic procrastination, perfectionism, and control: Associations with vigilant and avoidant coping. Journal of Social Behavior and Personality, $15(5), 35-46$.

[14] Liu G., \& Zhang J. (2017). Characteristics and Trends of Educational Psychology Research_ On the Basis of the Analysis of Published Articles in the Journal of Educational Psychology 2011-2015. Journal of Shandong Normal University (Humanities and Social Sciences Edition), 62 (4), 123-132. 